\title{
Two Distinct Uricase II (Nodulin 35) Genes Are Differentially Expressed in Soybean Plants
}

\author{
Ken-ichi Takane, ${ }^{1}$ Shigeyuki Tajima, ${ }^{1}$ and Hiroshi Kouchi ${ }^{2}$ \\ ${ }^{1}$ Department of Agriculture, Kagawa University, Miki-cho, Kida-gun, Kagawa, 761-07 Japan; and \\ ${ }^{2}$ Department of Plant Physiology, National Institute of Agrobiological Resources, Tsukuba, Ibaraki, \\ 305 Japan \\ Received 22 January 1997. Accepted 2 May 1997.
}

\begin{abstract}
Nodule-specific uricase (uricase II) is a homotetramer of a 33-kDa polypeptide, nodulin 35, and plays a key role in the assimilation of nitrogen fixed by microsymbionts in most legumes that have determinate nodules. We have isolated two distinct genes, $U R 2$ and $U R 9$, that encode for nodulin 35 from a soybean genomic library. Their corresponding cDNAs were also isolated from a nodule cDNA library. $U R 2$ and $U R 9$ both encode for 309 amino acid proteins with 12 amino acid differences. The expression of these two genes in various organs of soybean was examined by reverse transcription-polymerase chain reaction with primers specific to each cDNA sequences. Expression of $U R 9$ was almost specific in root nodules, although it was expressed in roots, primary leaves, and developing seed at very low levels. In contrast, the $U \boldsymbol{R} 2$ transcripts were present in almost all plant organs at low levels, but no enhancement of the expression was observed in nodules. Thus, $U R 9$ behaves as a nodulin gene, whereas $U R 2$ is a nonsymbiotic uricase II gene. The sequences of their potential promoter regions share high homology within regions up to about $400 \mathrm{bp}$ upstream from the translation initiation sites. These results suggest that symbiotic and nonsymbiotic uricase II genes diverged by gene duplication and that relatively small alterations in the promoter sequence enable the nodule-specific expression.
\end{abstract}

Legume plants form root nodules in symbiotic association with soilborne bacteria of the genera Rhizobium, Bradyrhizobium, and Azorhizobium, in which the bacteria are capable of reducing atmospheric nitrogen to ammonia. Formation of nitrogen-fixing nodules is accompanied by specific induction of a set of plant genes called nodulin genes (Van Kammen 1984). Although the exact functions of most of them are yet to be determined, nodulin genes are considered to play essential roles in nodule organogenesis and/or symbiotic nitrogen fixation (Nap and Bisseling 1990). Among the nodulin genes, nodulin 35 , a homotetramer of which is nodule-specific uricase

Corresponding author: Hiroshi Kouchi; Phone: (81-298) 38-8377; Fax: (81-298) 38-8347; E-mail: kouchih@ @s.abr.affrc.go.jp

Nucleotide and/or amino acid sequence data have been submitted to the GSDB, DDBJ, EMBL, and NCBI data bases as accession numbers AB002809 (UR2 cDNA), AB002810 (UR9 cDNA), AB002807 (UR2 promoter), and $\mathrm{AB} 002808$ (UR9 promoter). (uricase II, EC.1.7.3.3) in determinate nodules, is one with well-defined functions. Uricase II is localized in peroxisomes in uninfected cells in nodules (Bergman et al. 1983) and has an essential role in biosynthesis of ureide, which is the major form of transport of fixed nitrogen from nodules to the shoots in legumes forming determinate nodules (for review, see Tajima and Kouchi 1996).

The regulation mechanisms of nodulin gene expression are still unknown. Nodulin genes are divided into early and late nodulin genes according to the timing of the first appearance of their transcripts during nodule development. Nodulin 35 has been conventionally classified as a late nodulin that appears almost concomitantly with the onset of nitrogen fixation (Delauney and Verma 1988). However, a significant accumulation of nodulin $35 \mathrm{mRNA}$ appears well before the onset of nitrogen fixation and the level of the transcripts increases drastically with the onset of nitrogen fixation, suggesting a two-step control of nodulin 35 induction (Tajima et al. 1991). It has been suggested that the majority of late nodulin genes, such as leghemoglobin and nodulins 23 and 24, share common regulatory mechanism(s) (Mauro et al. 1985; Mauro and Verma 1988). Nodulin 35 expression is restricted in the uninfected cells in nodules, and thus its regulation mechanisms are considered to be totally different from those of other late nodulin genes, which are expressed in bacterial-infected cells (Mauro and Verma 1988).

In our attempts to elucidate the regulation mechanisms of nodulin 35 gene expression in root nodules, we have isolated two distinct genes of soybean, both encoding nodulin 35 . In the present paper, we describe the structure and expression of these genes. Interestingly, one of these genes is expressed in almost all plant organs at low levels and is not enhanced in root nodules, whereas the other clearly shows nodule-specific expression. The identification of a nonsymbiotic uricase II gene is intriguing from the view that nodulin genes may be organized by recruitment of pre-existing genes required for processes common to all plants (Mylona et al. 1995; Andersson et al. 1996).

\section{RESULTS}

Isolation of genomic and cDNA clones for uricase II.

A genomic library of soybean (Glycine max L. cv. Akisengoku) was screened with nodulin 35 cDNA (Takane et al. 1997) as a probe. As a consequence, we isolated two distinct 
genes, $U R 2$ and $U R 9$, brief restriction maps of which are shown in Figure 1. The nucleotide sequences of the EcoRI/ PstI fragment of UR2 and the XhoI/EcoRI fragment of UR9 were determined and compared with those of a soybean nodulin 35 gene and cDNA previously reported. These fragments both contain the first exon as well as about $1 \mathrm{~kb} 5^{\prime}$ upstream region and a part of the first intron. Upstream sequences up to about 400 bp from the translation initiation codon are highly homologous between $U R 2$ and $U R 9$ (Fig. 2), but more upstream sequences show no similarity (data not shown). The sequence of the first exon of UR2 was completely identical with that of a genomic sequence from cv. Dare (Nguyen et al. 1985), whereas that of UR9 was $97.1 \%$ identical with that of a cDNA from cv. Prize (Nguyen et al. 1985; Suzuki and Verma 1991).

Consequently, we have isolated full-length cDNA clones for $U R 2$ and $U R 9$ from a nodule cDNA library. Their nucleotide and predicted amino acid sequences are shown in Figure 3. The nucleotide sequences of $U R 2$ and $U R 9 \mathrm{cDNAs}$ were more than $99.8 \%$ identical to a cDNA sequence deduced from a genomic clone of cv. Dare and a cDNA sequence from cv. Prize, respectively (Nguyen et al. 1985; Suzuki and Verma 1991). UR2 and UR9 both encode 309 amino acid polypeptides with 12 amino acid differences. The deduced amino acid sequence of $U R 9$ contains 2 amino acid differences with that of cv. Prize, whereas that of $U R 2$ shows 1 amino acid difference with that of cv. Dare.

Nguyen et al. (1985) have suggested that a number of single-base-pair differences between a genomic clone from Dare and a cDNA clone from Prize might be due to genetic divergence between soybean cultivars. In the present work, however, both sequences were found in the genome of a single cultivar and both were expressed in the nodules. To confirm the presence of mRNAs of these two uricase II genes in vari- ous cultivars of soybean including Dare and Prize, we employed reverse transcription-polymerase chain reaction (RTPCR) with primers specific to each $U R 2$ and $U R 9$ sequence. The primer sequences are indicated in Figure 3 (positions 1 and 3). Specific amplification of $U R 2$ and $U R 9$ sequences with the respective primer combinations was demonstrated by the restriction site patterns within the sequences between the primers that are unique to $U R 2$ and $U R 9$. The results are shown in Figure 4, indicating that both $U R 2$ and $U R 9$ mRNAs are present in the nodules of all cultivars tested.

Figure 5 shows Southern blot analysis of soybean genomic DNA. Since the sequences of the first introns are considerably different between $U R 2$ and $U R 9$ genes (Fig. 2), we amplified these sequences by PCR from UR2 and UR 9 genomic clones and used them as specific probes. There was no hybridization band common between $U R 2$ and $U R 9$. The UR2 probe contains neither an EcoRI nor a HindIII site, whereas the UR9 probe contains an EcoRI site. Two hybridizing bands appeared only in EcoRI-digested soybean DNA probed with the UR9 probe. Thus, the results suggest strongly that the soybean genome contains one copy each of the $U R 2$ and $U R 9$ genes.

Taken together, these results indicate that $U R 2$ and $U R 9$ are different genes and do not represent allelic sequences.

\section{Expression of two uricase II genes in soybean tissues.}

Since the nucleotide sequences of $U R 2$ and $U R 9$ cDNAs are highly homologous, the expression analysis of the individual genes was only possible by RT-PCR with UR2- and UR9specific primer combinations. We designed such primer combinations to amplify the DNA fragments of different sizes for $U R 2$ and $U R 9$ to enable the reaction in a single tube for both $U R 2$ and $U R 9$ (in Figure 3, positions 1 and 3 for $U R 2$, and positions 2 and 3 for $U R 9$ ). Figure 6 shows the results of analysis during nodule development. The $U R 2$ and $U R 9$ transcripts
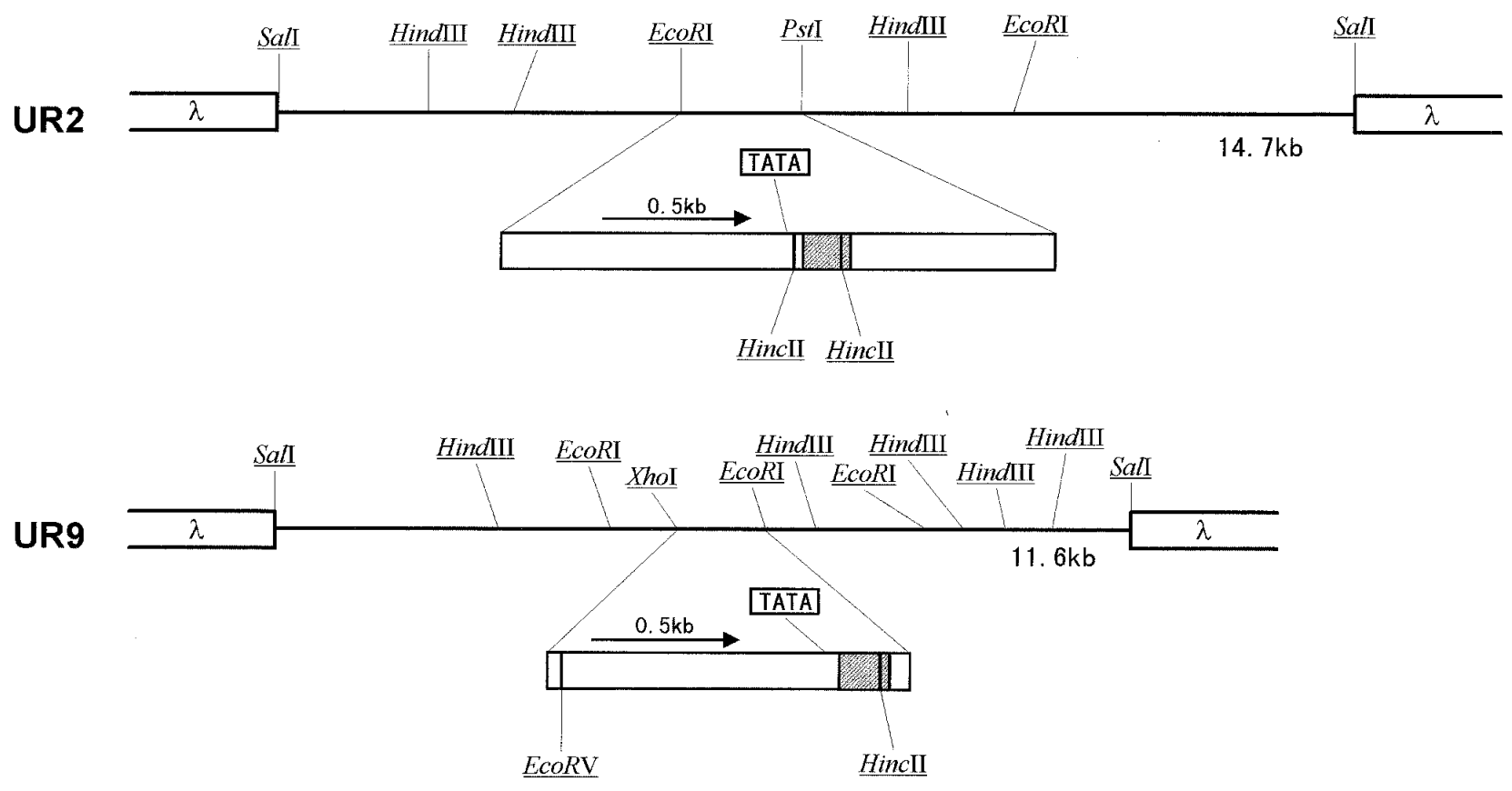

Fig. 1. Brief restriction maps of $U R 2$ and $U R 9$. The fragments containing potential promoter region and the first exon, sequences of which are shown in Figure 2, are magnified below the maps of lambda phages carrying an original insert (hatched area, first exon). 
were both present in uninfected roots at low levels, but the $U R 2$ mRNA was more abundant than the UR 9 mRNA. The detection of nodulin 35 mRNAs in uninfected roots is not surprising because Northern (RNA) blot hybridization of RNAs from uninfected roots with a nodulin $35 \mathrm{cDNA}$ probe also gave a weak signal after long exposure (data not shown). UR9 expression was obviously enhanced 7 days after sowing and Bradyrhizobium japonicum inoculation, coinciding well with our previous result with Northern hybridization (Tajima et al. 1991). The abundance of the UR9 mRNA was significantly higher in 10-day-old nodules than in uninfected roots. In contrast, the level of the $U R 2$ transcripts remained at an almost constant level during the nodulation process and there was no difference between uninfected roots and 10-day nodules.

Similar RT-PCR experiments were carried out with RNAs from various tissues of soybean (Fig. 7). The $U R 9$ transcripts were most abundant in nodules but were also detected in uninfected tissues at very low levels, whereas the $U R 2$ transcripts were detected at similar levels in almost all tissues except de- veloping seeds, and there was no specific enhancement in nodules. In the tissues other than nodules, the level of the $U R 9$ transcripts was relatively high in primary leaves and developing seeds. Recently, we have isolated nodulin 35 cDNA from developing seeds that showed exactly the same sequence as UR9 (Takane et al. 1997).

\section{DISCUSSION}

In the present work, we have identified two closely related but different uricase II genes, $U R 2$ and $U R 9$, that are expressed differentially in various organs of soybean plants. The cDNA sequences of $U R 2$ and $U R 9$ were almost identical with those previously reported for soybean cultivars Dare and Prize, respectively. It has been previously postulated that several single-base-pair differences between these two sequences are due to varietal difference (Nguyen et al. 1985). However, the results presented in this paper demonstrate that $U R 2$ and $U R 9$ are different genes and that their mRNAs are both pres-

\begin{tabular}{|c|c|c|}
\hline & -408 & \\
\hline UR2 & TGGGGGCACAAGGTTAGCAACTAGTTTAGTTTAGCATATAAATTAGAT-----GTCCGTACTTGCTITAACTTATTTCAAAACAATTAATTACC & -320 \\
\hline UR9 & $\begin{array}{l}\text { A. TAAATT CTTTC. . TA. AA. A. G. . A. . A. . . C. . . . C. ACATTCAC. . . } \ldots \ldots \ldots \ldots \ldots \ldots \ldots \ldots \text { T. . С. . A. T. } \ldots \\
-403\end{array}$ & -310 \\
\hline UR2 & TTCATATTCTCCACGTCCTTATCCTATAGTAGCAACATCA--_-_-_-_-CGACACATCTATGATTTTCCAAGTTGAGAGTTTTCTCACGTA & -238 \\
\hline UR9 & $\ldots \ldots \ldots \ldots \ldots \ldots \ldots \ldots$ & -216 \\
\hline UR2 & ATAAGTTCATAGAAAATTTTGGAGTACCAATTATTATGTGTTTAGGAAGAGATTCAACAATCTTCGTCCTAA-CCTATTTGTAGCAAGAAATTG & -144 \\
\hline UR9 & $\ldots$ T. . С. . . С. T. . . С. .- & -152 \\
\hline UR2 & AATTGAAAAATTTATAACAATTTGTTTGGACAATGATGTAATGTAAGGGC-----GCACACAGAGTTACTGAGAGG-GGGGAAAGTAAAACCGG & -56 \\
\hline UR9 & 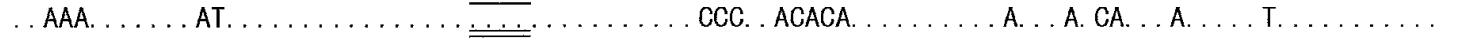 & -58 \\
\hline & 1 & \\
\hline UR2 & CAAACACGGCCTTGTCCTCACACGATACACACACA--TATAAATAGGGCGAAAACTCAATAG--TTAA-----CTCAAACA----TTCTTCAGTT & 27 \\
\hline UR9 & $\ldots \ldots G \ldots \ldots \ldots \ldots \ldots G \ldots$ G. . G. . GG & 37 \\
\hline UR2 & CTAAGAAACCTTAAAAA--ACAA-GTAG---TGTTCCGAAAAGATGGCTCAGCAGGAAGTGGTAGAAGGGTTCAAGTTCGAACAGAGGCACGGG & 115 \\
\hline UR9 & 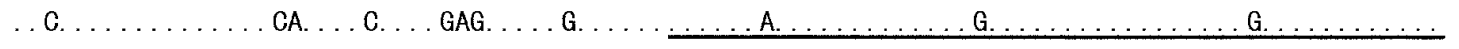 & 131 \\
\hline UR2 & AAAGAGGGGGTGAGAGTGGGGGGGGTGTGGAAGAGGAGGGAGGGGGAGCACTTCGTTGTGGAGTGGGGCGTGGGCATCACTCTCTTCTCAGACT & 209 \\
\hline UR9 & А. A. & 225 \\
\hline UR2 & GCGTCAACTCGTATCTCCGCGATGACAACTCTGACATCGTTGCTACTGATACCATGAAAAACACAGTAACAACCTGAACCTTCTCAGTTCTCAC & 303 \\
\hline UR9 & $\ldots \ldots$ & 319 \\
\hline UR2 & ----CCGCTATTTGTTTTTT-CTCTTTCTTTCTTTCTATTTTTATTATTGATTTCTGTTTTTTTTTTTTACCGT & 394 \\
\hline UR9 & TCAC. . A. . T. . T. . A. TA. T. C. . . . G. . A. . . . . G. . A. & 413 \\
\hline UR2 & TCGTTTTCA & 488 \\
\hline UR9 & GTTTCTGTGAAGTTGAATTTATGCAGAACAGGAAATGTTTGCCTGTGGTTGTGTGAAAGTACAATGTCATTTACCACTTGATCATTTTCGTCTG & 507 \\
\hline UR2 & CCCTAATTAAGATTTTTGACATTTT & 585 \\
\hline UR9 & TTTATGTTTACCATCGTCAGCTCACTGAGTTTT & 540 \\
\hline UR2 & TCTTGATATATCTCCACAAATTTTGGTCATTTGGGTCAGATTTGGAATTGCTTTAATTTTGATCATGACACACCCTTGTTTTGTTTCACACCTTT & 679 \\
\hline UR2 & CACTACAGAGGAGTGAGTGAAATTCATCTTTTTATTGTATTTTTGGGTGTTTGGAGGAGAGAGGCTGAGCGGTGCAACTTGAACTTGTTTGCTC & 774 \\
\hline U & AGTTCATGATCATTACTCATTACTCAATGAGTTTCACTGCTTGAATTTTTCTAATTTT & 832 \\
\hline
\end{tabular}

Fig. 2. Comparison of promoter sequences of $U R 2$ and $U R 9$. An EcoRI/Pst fragment of $U R 2$ and XhoI/EcoRI fragment of $U R 9$ genomic clones were sequenced entirely. The gaps (-) are introduced to optimize the alignment and identical nucleotides are indicated by dots. The first exons are underlined. A transcription initiation site of UR2 (Nguyen et al. 1985) is numbered as 1. "TATA" and "CAAT" boxes are double-underlined. A sequence motif referred in the text is boxed. 




Fig. 3. cDNA and deduced amino acid sequences of $U R 2$ and $U R 9$. Identical nucleotides are indicated by dots and identical amino acids are shown by asterisks. The primer sequences used for reverse-transcription-polymerase chain reaction analysis are shaded. The potential poly(A) addition signals are underlined. 


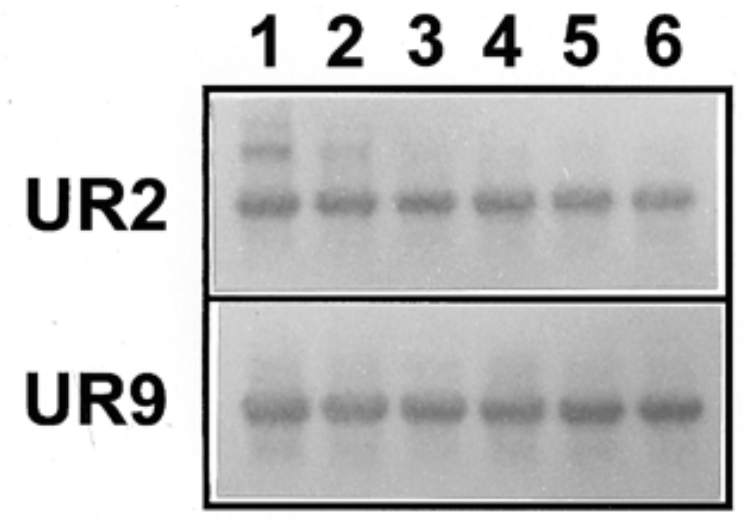

Fig. 4. Reverse transcription-polymerase chain reaction (RT-PCR) analysis of total RNAs isolated from nodules of various varieties of soybean. Five nanograms of total RNA was reverse transcribed and then the cDNA was amplified by a 20 -cycle PCR with forward primers at position 1 in Figure 3 and reverse primers at position 3. Lane 1, Dare; lane 2, Prize; lane 3, Toyosuzu; lane 4, Midorimame; lane 5, Enrei; lane 6, Okushirome.

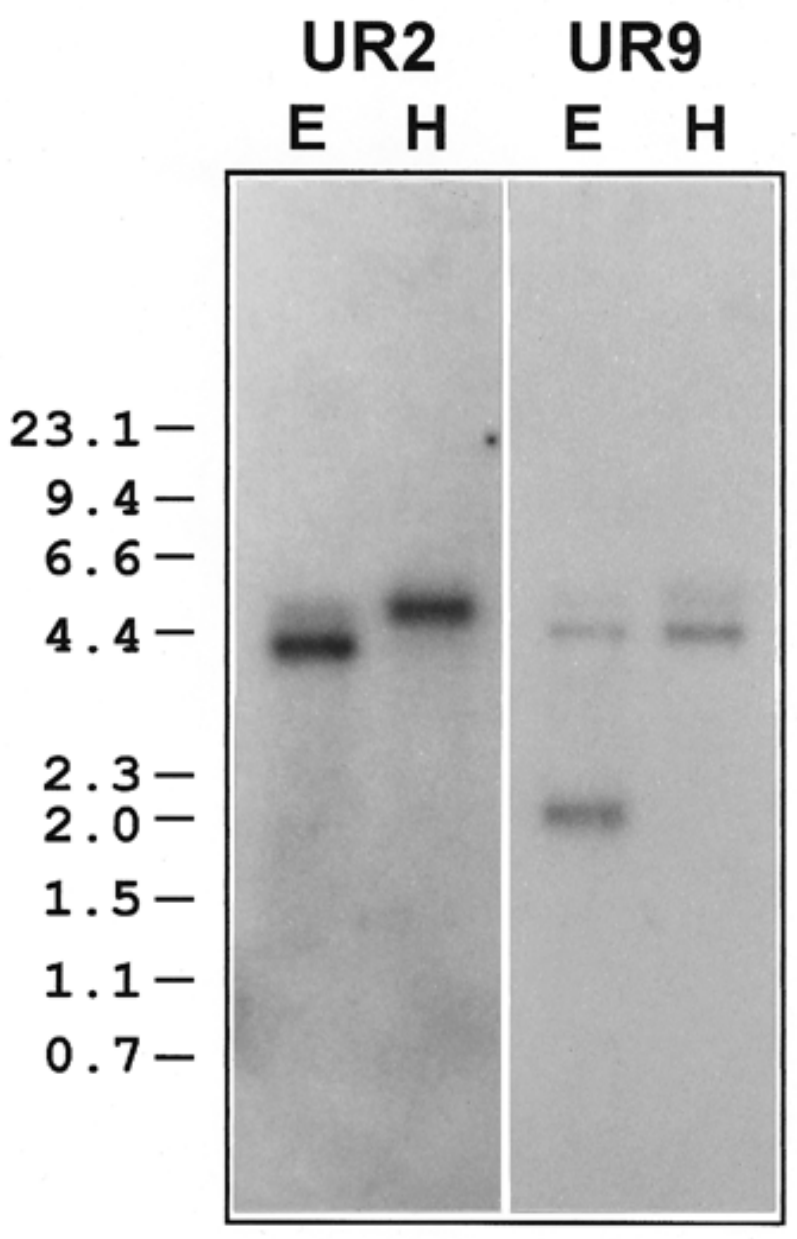

Fig. 5. Southern blot hybridization of genomic DNA of soybean (cv. Akisengoku). Ten micrograms of DNA was digested completely with EcoRI (lane 1) and HindIII (lane 2), and electrophoresed on a $0.8 \%$ agarose gel. The DNAs were transferred to a Hybond-N membrane and probed with ${ }^{32} \mathrm{P}$-labeled DNA fragments of the first intron of UR2 (A) and $U R 9(\mathbf{B})$. Marker sizes are shown in kilobase pairs. ent in all soybean cultivars tested (Fig. 5). Interestingly, the analysis with RT-PCR (Figs. 6 and 7) revealed that the $U R 2$ transcripts are present in almost all plant organs at low levels and there is no significant enhancement of $U R 2$ expression in nodules. In contrast, $U R 9$ expression was almost specific to root nodules, although UR 9 was expressed in roots, primary leaves, and developing seed at very low levels. These results indicate that $U R 2$ is a nonsymbiotic uricase II gene.

In recent years, it has been proposed that nodulin genes have arisen by recruitment of pre-existing, nonsymbiotic genes, which might have roles in functions common in all plants (Mylona et al. 1995; Andersson et al. 1996). A number of structural and/or functional homologues of nodulin genes have been found in nonlegume plants; for instance, those of leghemoglobin (Jacobsen-Lyon et al. 1995; Taylor et al. 1994), ENOD40 (Van de Sande et al. 1996), and nodulin 26 (Miao and Verma 1993). In particular, identification of symbiotic and nonsymbiotic (leg)hemoglobin genes from both a nonlegume, Casuarina glauca, and the legume soybean suggests strongly that the leghemoglobin gene family has diverged from nonsymbiotic hemoglobin genes through gene duplication (Jacobsen-Lyon et al. 1995; Andersson et al. 1996).

Identification of a nonsymbiotic uricase II gene in soybean also supports this hypothesis. In the case of soybean (leg)hemoglobin genes, however, the predicted amino acid sequence

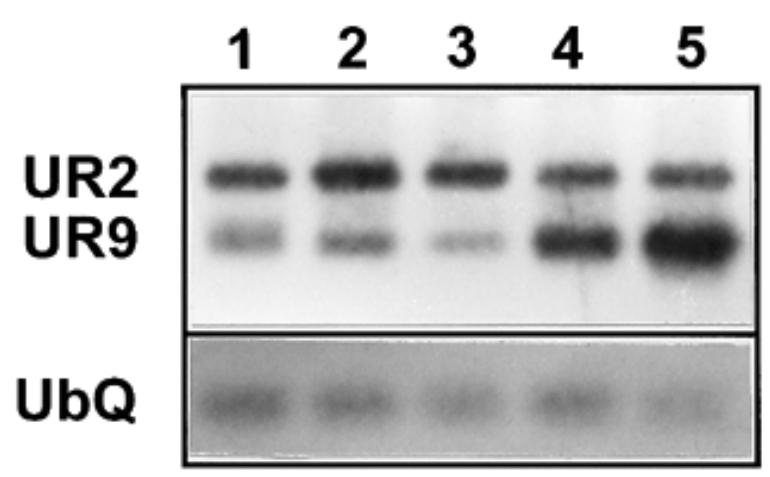

Fig. 6. Expression of $U R 2$ and $U R 9$ during early stage of nodulation. Amplification of $U R 2$ and $U R 9$ fragments was performed in the same reaction with primers at positions 1 and 3 (for UR2) and at positions 2 and 3 (for $U R 9$ ) in Figure 3. Lane 1, uninfected roots (3 days); lane 2, infected roots ( 3 days); lane 3 , infected roots (5 days); lane 4 , nodulated roots ( 7 days); lane 5, nodules (10 days). Infected and nodulated roots are the root segments of a portion on which nodules would appear or appeared. Ubiquitin (UbQ) was also amplified as an internal standard.

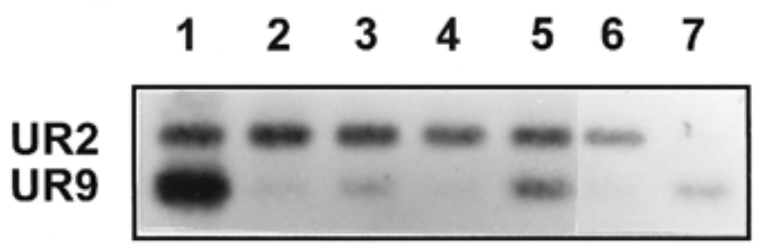

Fig. 7. Detection of $U R 2$ and $U R 9$ transcripts in various soybean tissues. Reverse transcription-polymerase chain reaction conditions were exactly the same as those in Figure. 6. Lane 1, nodules (13 days); lane 2, uninfected root tips ( 3 days); lane 3 , uninfected roots (6 days, only basal parts); lane 4 , stems (7 days); lane 5, primary leaves ( 7 days); lane 6 , shoot apices ( 7 days); lane 7, developing seeds ( 29 days after flowering). 
of a nonsymbiotic gene is considerably different from that of a symbiotic leghemoglobin gene (58\% identity) and a phylogenetic tree analysis of symbiotic and nonsymbiotic hemoglobins from many plant species indicates that they are clustered in different gene families (Andersson et al. 1996). On the other hand, predicted amino acid sequences of $U R 2$ and $U R 9$ are $96 \%$ identical and their nucleotide sequences of the potential promoter region as well as the 3 '-noncoding region are also highly homologous. Thus, symbiotic and nonsymbiotic uricase II genes are more closely related to each other than symbiotic and nonsymbiotic hemoglobin genes are. Furthermore, the tissue specificity of $U R 2$ and $U R 9$ expression is much more redundant than that of symbiotic and nonsymbiotic hemoglobin gene expression. Although UR9 gene expression is drastically enhanced in root nodules, it is also expressed in nonsymbiotic tissues at very low levels (Figs. 6 and 7; see also Takane et al. 1997). These findings may imply that the nodule-specific uricase II gene diverged from nonsymbiotic uricase II genes more recently than the similar divergence in leghemoglobin genes. In fact, it has been strongly suggested that the leghemoglobin gene family arose before speciation occurred within legume plants (Andersson et al. 1996). Nodule-specific uricase II is found only in the ureideproducing legumes, suggesting that it was recruited from the housekeeping uricase II genes after ureide-translocating and amide-translocating legumes diverged from each other.

The promoter sequences of $U R 2$ and $U R 9$ are highly homologous up to about $400 \mathrm{bp}$ from their translation initiation sites (Fig. 2), but do not contain any motifs that have been shown to be important for nodule-specific expression (nodulin boxes; Ramlov et al. 1993). This is not surprising, because nodulin 35 expression is specific in the uninfected cells of nodules, whereas nodulin boxes have been identified in late nodulin genes that are specifically induced in the infected cells (Mauro et al. 1985; Mauro and Verma 1988). Nonsymbiotic hemoglobin gene promoters contain a motif that is critical for their expression and it has been postulated to be a nonsymbiotic motif (Andersson et al. 1996). This motif, GAA GAG, is present only in the $U R 2$ promoter (Fig. 2, boxed), whereas a 35-bp sequence including this motif is absent in $U R 9$ promoter. Although the position of this motif is more upstream in the $U R 2$ promoter than it is in the nonsymbiotic hemoglobin promoters, the motif may have a regulatory role for expression not specific to symbiotic tissues. At most, small difference(s) in the promoter sequences might be responsible for the transition from expressing a uricase II gene at low levels to high levels in nodules. Identification and promoter analysis of uricase II genes from nonlegume plants may provide more clues for understanding the mechanisms underlying the transition that occurred during the course of evolution. So far, we have found, from a GenBank/EMBL data base search, the presence of an Arabidopsis expression sequence tag that shows extensive homology to the uricase II protein (accession R89941; Newman et al. 1994).

Preliminary experiments with a $U R 9$ promoter:: $\beta$-glucuronidase gene fusion transformed into soybean hairy roots indicated that an approximately 400-bp, 5'-flanking region from translation start is sufficient to ensure nodule-uninfected, cellspecific expression of this gene (K. Takane, unpublished results). However, similar experiments for the UR2 promoter resulted in an inappropriately low and unstable level of ex- pression. Therefore, further investigation is clearly needed to confirm the differential activities of $U R 2$ and $U R 9$ promoters in transgenic plants.

\section{MATERIALS AND METHODS}

\section{Plant materials and isolation of DNA and RNA.}

Soybean plants (Glycine max L. cv. Akisengoku) were grown with or without inoculation of Bradyrhizobium japonicum strain A1017 as described previously (Kouchi and Hata 1993). Nodulated roots, nodules, roots, stems, shoot apices, and primary leaves were harvested from 3- to 18-day-old seedlings. Developing seeds were harvested from field-grown plants 29 days after flowering. Mature nodules were also harvested from various soybean cultivars grown on vermiculite. Total RNAs were isolated by guanidium thiocyanate extraction followed by gradient centrifugation on cesium chloride as described previously (Kouchi et al. 1989). The poly(A) ${ }^{+}$ RNA-enriched fraction was selected by oligo(dT)-cellulose column chromatography by standard procedures (Sambrook et al. 1989). Genomic DNA was isolated from hypocotyls of 7day-old etiolated seedlings by the method of Rogers and Bendich (1988).

\section{Isolation of nodulin 35 genomic clones.}

A genomic library was constructed in $\lambda$ EMBL3 (Stratagene. La Jolla, CA) from size-fractionated, partial Sau3AI-digested DNA, and screened with ${ }^{32} \mathrm{P}$-labeled nodulin 35 cDNA (Takane et al. 1997) by standard methods (Sambrook et al. 1989). Positive clones were purified and appropriate fragments of the inserts were subcloned into pBluescript II SK+ for further analysis.

\section{DNA sequencing.}

Isolated DNAs were sequenced by the dideoxy chain termination method (Sanger et al. 1977) with an automatic sequencer (model 370A, Applied Biosystems, Foster City, CA). Both strands were sequenced entirely.

\section{Genomic DNA transfer blot analysis.}

Soybean genomic DNA $(15 \mu \mathrm{g})$ was digested by EcoRI or HindIII to completion, electrophoresed on a $0.8 \%$ agarose gel, and transferred to a nylon membrane (Hybond-N, Amersham, UK). The DNA fragments corresponding to first introns of $U R 2$ and $U R 9$ were prepared by PCR from the genomic clones, ${ }^{32} \mathrm{P}$-labeled, and used as probes. Hybridization was carried out in $50 \%$ formamide, $4.8 \times \mathrm{SSC}(1 \times \mathrm{SSC}$ is $0.14 \mathrm{M}$ $\mathrm{NaCl}$ plus $0.015 \mathrm{M}$ sodium citrate), $5 \times$ Denhardt's solution, $0.5 \%$ sodium dodecyl sulfate (SDS), $50 \mathrm{mM} \mathrm{N}$-2-hydroxyethylpiperazine- $N$ '-2-ethanesulfonic acid (HEPES), $\mathrm{pH} 7.3$ and $100 \mu \mathrm{g}$ of denatured salmon sperm DNA per ml at $42^{\circ} \mathrm{C}$ for more than $16 \mathrm{~h}$. The filter was washed in $2 \times \mathrm{SSC}, 0.5 \%$ SDS for $30 \mathrm{~min}$ at room temperature, and then in $0.2 \times \mathrm{SSC}$, $0.1 \% \mathrm{SDS}$ at $55^{\circ} \mathrm{C} 4$ times for $10 \mathrm{~min}$ each.

\section{Isolation of cDNA clones for UR2 and UR9.}

A nodule cDNA library was constructed in $\lambda \mathrm{gt} 10$ from poly $(\mathrm{A})^{+}$RNA of 9-day-old soybean nodules as described (Kouchi and Hata 1993) and screened with ${ }^{32}$ P-labeled nodulin 35 cDNA (Takane et al. 1997). Purified $\lambda$ phages were tested by PCR with primer combinations specific to $U R 2$ and $U R 9$ 
designed from the sequences of genomic clones. Among 15 clones tested, four and 11 clones gave a band of expected size with $U R 2$-specific and $U R 9$-specific primers, respectively. The clones with the longest inserts were selected from each group and subcloned into pBluescript.

\section{RT-PCR analysis.}

Total RNAs from various tissues of soybean were reversetranscribed by AMV reverse transcriptase (Seikagaku-Kogyo, Tokyo) with oligo(dT) $)_{12-18}$ primer. The synthesized cDNA (equivalent to $5 \mathrm{ng}$ of RNA) was amplified in 20 cycles of PCR $\left(94^{\circ} \mathrm{C}, 1 \mathrm{~min} ; 58^{\circ} \mathrm{C}, 1 \mathrm{~min} ; 72^{\circ} \mathrm{C}, 2 \mathrm{~min}\right)$ with the Expand High Fidelity PCR System (Boehringer-Mannheim, Mannheim, Germany). Sequences of oligonucleotide primers for PCR are shown in Figure 2. To detect $U R 2$ and $U R 9$ mRNAs in nodules of various soybean varieties, we used the primers that amplify the fragment of same length for $U R 2$ and $U R 9$, and therefore the PCRs were performed in separate tubes with the same cDNA preparation as templates. In all other experiments, the primers that give amplified DNA with different length for $U R 2$ and $U R 9$ were used in a single tube. Ubiquitin primers (Minami et al. 1996) were included in every reaction as an internal standard. The amplified DNAs were electrophoresed on a $1 \%$ agarose gel and transferred to nylon membranes. The membranes were probed with digoxigeninlabeled nodulin 35 cDNA. The conditions of hybridization and subsequent washings were the same as those of genomic DNA transfer blot analysis. The hybridization signals were detected by antidigoxigenin-alkaline phosphatase conjugate (Boehringer-Mannheim) with CDP-Star (Boehringer-Mannheim) as a substrate, according to the manufacturer's manual.

\section{ACKNOWLEDGMENTS}

This research was supported in part by the Bio-Media Program from The Ministry of Agriculture and Forestry and Fisheries, Japan, to H. K. and S. T. (BMP-97-IV-1-1) and by a Grant-in-Aid from The Japan Society for Promotion of Sciences to H. K.

\section{LITERATURE CITED}

Andersson, C. R., Jensen, E. O., Llewellyn, D. J., Dennis, E. S., and Peacock, W. J. 1996. A new hemoglobin gene from soybean: A role for hemoglobin in all plants. Proc. Natl. Acad. Sci. USA 93:56825687.

Bergmann, H., Preddie, E. P., and Verma, D. P. S. 1983. Nodulin-35: A subunit of specific uricase (uricase II) induced and localized in the uninfected cells of soybean nodules. EMBO J. 2:2333-2339.

Delauney, A. J., and Verma, D. P. S. 1988. Cloned nodulin genes for symbiotic nitrogen fixation. Plant Mol. Biol. Rep. 6:279-285.

Jacobsen-Lyon, K., Jensen, E. O., Jorgensen, J. E., Marcker, K. A., Peacock, W. J., and Dennis, E. S. 1995. Symbiotic and nonsymbiotic hemoglobin genes of Casuarina glauca. Plant Cell 7:213-223

Kouchi, H., and Hata, S. 1993. Isolation and characterization of novel nodulin cDNAs representing genes expressed at early stages of soybean nodule development. Mol. Gen. Genet. 238:106-119.

Kouchi, H., Tsukamoto, M., and Tajima, S. 1989. Differential expression of nodule-specific (nodulin) genes in the infected, uninfected and cortical cells of soybean (Glycine max) root nodules. J. Plant Physiol. 135:608-617.

Mauro, V. P., Nguyen, T., Katinakis, P., and Verma, D. P. S. 1985. Primary structure of soybean nodulin- 23 and potential regulatory elements in the $5^{\prime}$-flanking regions of nodulins and leghemoglobin genes. Nucleic Acid Res. 13:239-249.

Mauro, V. P., and Verma, D. P. S. 1988. Transcriptional activation in nuclei from uninfected soybean of a set of genes involved in symbiosis with Rhizobium. Mol. Plant-Microbe Interact. 1:46-51.

Miao, G. H., and Verma, D. P. S. 1993. Soybean nodulin-26 gene encoding a channel protein is expressed only in the infected cells of nodules and is regulated differently in roots of homologous and heterologous plants. Plant Cell 5:781-794.

Minami, E., Kouchi, H., Cohn, J. R., Ogawa, T., and Stacey, G. 1996. Expression of the early nodulin, ENOD40, in soybean roots in response to various lipo-chitin signal molecules. Plant J. 10:23-32.

Mylona, P., Pawlowski, K., and Bisseling, T. 1995. Symbiotic nitrogen fixation. Plant Cell 7:869-885.

Nap, J.-P., and Bisseling, T. 1990. Developmental biology of a plantprokaryote symbiosis: The legume root nodule. Science 250:948-954

Newman, T., de Bruijn, F. J., Green, P., Keegstra, K., Kende, H., McIntosh, L., Ohlrogge, J., Raikhel, N., Sommerville, S., Thomashow, M., Retzel, E., and Sommerville, C. 1994. Genes galore: A summary of methods for accessing results from large-scale partial sequencing of anonymous Arabidopsis cDNA clones. Plant Physiol. 106:1241-1255.

Nguyen, T., Zelechowska, M., Foster, V., Bergmann, H., and Verma, D. P. S. 1985. Primary structure of the soybean nodulin-35 gene encoding uricase II localized in the peroxisomes of uninfected cells of nodules. Proc. Natl. Acad. Sci. USA 82:5040-5044.

Ramlov, K. B., Laursen, N. B., Stougaard, J., and Marcker, K. A. 1993. Site-directed mutagenesis of the organ-specific element in the soybean leghemoglobin lbc3 gene promoter. Plant J. 4:577-580.

Rogers, S. O., and Bendich, A. J. 1988. Extraction of DNA from plant tissues. Pages A6/1-A6/11 in: Plant Molecular Biology Manual. S. B. Gelvin, R. A. Schilperoort, and D. P. S. Verma, eds. Kluwer Academic Pub., Dordrecht, The Netherlands.

Sambrook, J., Fritsch, E. F., and Maniatis, T. A. 1989. Molecular Cloning: A Laboratory Manual. 2nd ed. Cold Spring Harbor Laboratory, Cold Spring Harbor, NY.

Sanger, F., Nicklen, S., and Coulson, A. R. 1977. DNA sequencing with chain-terminating inhibitors. Proc. Natl. Acad. Sci. USA 74:54635467.

Suzuki, H., and Verma, D. P. S. 1991. Soybean nodule-specific uricase (nodulin-35) is expressed and assembled into a functional tetrameric holoenzyme in Escherichia coli. Plant Physiol. 95:384-389.

Tajima, S., Ito, H., Tanaka, K., Nanakado, T, Sugimoto, A., Kouchi, H., and Okazaki, K. 1991. Soybean cotyledons contain a uricase that cross-reacts with antibodies raised against the nodule uricase (nod35). Plant Cell Physiol. 32:1307-1311.

Tajima, S., and Kouchi, H. 1996. Metabolism and compartmentation of carbon and nitrogen in legume nodules. Pages 27-60 in: PlantMicrobe Interactions. G. Stacey and N. Keen, eds. Chapman/Hall, New York.

Takane, K., Tanaka, K., Tajima, S., Okazaki, K., and Kouchi, H. 1997. Expression of a gene for uricase II (Nodulin-35) in cotyledons of soybean plants. Plant Cell Physiol. 38:149-154.

Taylor, E. R., Nie, X. Z., MacGregor, A. W., and Hill, R. D. 1994. A cereal hemoglobin gene is expressed in seed and root tissues under anaerobic conditions. Plant Mol. Biol. 24:853-862.

Van de Sande, K., Pawlowski, K., Czaja, I., Wieneke, U., Schell, J., Schmidt, J., Walden, R., Matvienko, M., Wellink, J., Van Kammen, A., Franssen, H., and Bisseling, T. 1996. Modification of phytohormone response by a peptide encoded by ENOD40 of legumes and a nonlegume. Science 273:370-373.

Van Kammen, A. 1984. Suggested nomenclature for plant genes involved in nodulation and symbiosis. Plant Mol. Biol. Rep. 2:43-45. 